Bogotá: Banco de la República, Instituto Francés de Estudios Andinos, 2001. 580 pages

Frédéric Martinez. El nacionalismo cosmopolita. La referencia europea en la construcción nacional en Colombia, 1845-1900

\title{
Clément Thibaud
}

\section{(2) OpenEdition}

Journals

Edición electrónica

URL: http://journals.openedition.org/bifea/6870

DOI: $10.4000 /$ bifea.6870

ISSN: 2076-5827

Editor

Institut Français d'Études Andines

\section{Edición impresa}

Fecha de publicación: 1 agosto 2002

Paginación: 397-402

ISSN: 0303-7495

\section{Referencia electrónica}

Clément Thibaud, « Frédéric Martinez. El nacionalismo cosmopolita. La referencia europea en la construcción nacional en Colombia, 1845-1900 », Bulletin de l'Institut français d'études andines [En línea], 31 (2) | 2002, Publicado el 08 agosto 2002, consultado el 08 diciembre 2020. URL : http:// journals.openedition.org/bifea/6870; DOI : https://doi.org/10.4000/bifea.6870

\section{(c) (i) $\odot$}

Les contenus du Bulletin de l'Institut français d'études andines sont mis à disposition selon les termes de la licence Creative Commons Attribution - Pas d'Utilisation Commerciale - Pas de Modification 4.0 International. 


\section{COMPTES RENDUS D'OUVRAGES}

Frédéric Martinez, El nacionalismo cosmopolita. La referencia europea en la construcción nacional en Colombia, 1845-1900, Bogotá, Banco de la República Instituto Francés de Estudios Andinos, 2001, 580p.

El nacionalismo cosmopolita da un vuelco importante a dos conceptos capitales ligados a la construcción de las identidades nacionales en América Latina: el de la difusión de los modelos políticos occidentales y otro conexo, el del modelo centroperiferia, según los cuales las innovaciones de Europa habrían llegado a una periferia pasiva y marginalizada, en este caso Colombia. Reparando en las múltiples formas de referirse a Europa entre 1845 y 1900, el autor desbroza períodos de la historia cultural y política colombiana consideradas hasta ahora sin mayor interés.

En aquella época, Colombia trata de constituirse en nación. Desde el punto de vista cultural, las élites buscan definir valores comunes capaces de edificar una identidad coherente. En lo político se trata de conjurar la tradición de debilidad del Estado construyendo una administración eficaz e imparcial. Dentro de esta búsqueda, las élites colombianas se vuelcan hacia lo que ellas dan por sentado como el centro de la civilización: Europa. Desde 1845 examinan sin cesar, durante cincuenta años, las instituciones, la vida política social y cultural de algunos países faros: Francia a la cabeza, luego Gran Bretaña y enseguida Alemania, Italia y España. Atrayente para algunos, repulsivo para otros, este modelo europeo deviene en un interés fundamental de la vida nacional. ¿Es necesario copiar, como se piensa de buen grado hacia 1850, los aspectos positivos de la modernidad ultra atlántica? O por el contrario como se cree a fines de siglo ¿hay que adaptar las instituciones y las técnicas al carácter nacional salvaguardando al mismo tiempo los valores fundamentales de la sociedad colombiana — la religión católica, la civilización rural y el conservadurismo popular del campo-?

A través de esta maduración, en la que la opinión pasa de una devota admiración a un intento de instrumentalización de los éxitos europeos, se pone en juego un asunto fundamental ¿cómo cambiar el destino funesto que parecen imponer al país la compartimentación geográfica, la diseminación de la población en polos aislados, la 
casi inexistencia de transportes y la larga tradición de debilidad económica y administrativa, es decir la fragmentación y la dislocación? Frédéric Martinez escribe la historia melancólica de un doble fracaso, el de la edificación de un Estado regulador de la vida social, y su correlato, el de la construcción de una identidad nacional unificadora. Este balance desalentador y provisional, sólo ha sido posible a costa de efectuar una inversión de las problemáticas hasta ahora aceptadas en la historia de las relaciones entre Europa y su periferia.

\section{EL RECHAZO DEL MODELO DIFUSIONISTA}

$\mathrm{El}$ autor ataca con fuerza la abstracta concepción difusionista de las relaciones culturales, dominante hasta 1900. En efecto, a este modelo se le hacen dos graves objeciones: no tener en cuenta el carácter dinámico de la adopción de innovaciones europeas y olvidar que la difusión cultural se lleva a cabo con actores concretos: las ideas no se difunden por obra y gracia de su propia fuerza.

El modelo corriente de difusión cultural presupone que las ideas parten de un centro productor para informar a una periferia adormecida. El contrasentido fundamental de esta concepción se basa en la convicción de una relación disimétrica en el campo de la circulación cultural entre Europa y el resto del mundo. Por el contrario El Nacionalismo Cosmopolita detalla los vaivenes incesantes entre los dos continentes. Dentro de estos contactos, Colombia no estuvo inerte en el empleo de las ideas extranjeras. Los términos de "referencia a Europa" muestran la amplitud del cambio de perspectiva: lo que prima son los intereses locales, y a partir de ellos se construye la inconsistente noción de "modernidad europea".

En otros términos, la adopción de una institución, como la policía, la aceptación de una innovación técnica, o la "copia" de un establecimiento educativo o cultural, dependen de un proceso dinámico en el que el receptor es pues el que desempeña un rol motor. En vez de hablar de trasplante, Frédéric Martinez prefiere razonar en términos de adopción. La idea, la invención, la institución o las técnicas europeas son acogidas porque son deseadas por los actores colombianos, los mismos que tienen una necesidad concreta de ellas para responder a los intereses locales.

Aún más, este proceso de adopción posee una dimensión de metamorfosis: al atravesar el océano, la copia cambia de sentido. El caso más patente es la Revolución de 1848. Este ejemplo alimenta apasionados debates políticos; les permite a los liberales radicales colombianos forjarse un concepto positivo del rol del pueblo en la vida pública a pesar de las diferencias entre ambas sociedades. No quepan dudas: los artesanos urbanos de Bogotá serán la estampa colombiana de inencontrables obreros.

Porque el vuelco conceptual que produce El Nacionalismo Cosmopolita permite finalmente poner en relieve las relaciones ambiguas que mantenían los actores colombianos con el Viejo Continente. Lejos de ser un modelo aplastante, Europa ha sido a menudo objeto de repulsa simbólica e intelectual. Los conservadores que viajan a Francia o a Gran Bretaña están espantados por la miseria obrera, la inestabilidad política y la falta de piedad. Por reacción, se afirma un estereotipo colombiano que pone de manifiesto las relaciones contradictorias con el viejo mundo: si la Europa de las técnicas 
es grande por sus obras materiales, el Edén republicano y espiritual de América traza una línea infranqueable en materia de religión y de política.

Mientras más desbarata, a lo largo de su libro, el famoso "modelo" europeo, Frédéric Martinez logra mostrar mejor la fineza y la complejidad de las relaciones Europa-América. Aquí no hay ningún suspenso, ese modelo no existe ya que carece de consistencia y de unidad. Es tan ecléctico como los actores colombianos que se apoderan de él para construirlo, cada uno a su manera. En este sentido, el concepto centro-periferia vuela en pedazos; a lo más, esta circulación cultural y política se limita al estatuto de una referencia retórica, edificada por la multitud de puntos de vista colombianos sobre una Europa deseada y a la vez odiada pero sobre todo imaginaria.

Esto ocurre porque las élites colombianas tienen primero una relación instrumental con la cultura política del viejo continente. En efecto, tratan de construir una identidad específica con algunos ingredientes extranjeros sin que eso signifique querer importar de Europa la civilización. Cuando los diputados colombianos disertan largamente sobre las ventajas y los inconvenientes de los diferentes regímenes políticos, no es índice de una dominación sino prueba de una relación dinámica con la civilización del viejo continente, cuya historia y actualidad sirven de reservorio argumentativo en las batallas políticas locales. La amplitud y la naturaleza única de la experiencia histórica europea constituyen una caja de herramientas conceptual para las proposiciones identitarias. Y como la identidad colombiana no es objeto de consenso, la Europa imaginaria será unas veces católica y tradicionalista para los conservadores, otras veces moderna y francmasónica para los liberales.

\section{DEL PRETEXTO POLÉMICO AL ORDEN IMPORTADO: UNA NUEVA CRONOLOGÍA}

En un nivel más general, El Nacionalismo Cosmopolita busca elucidar "la articulación entre el proceso de construcción nacional y la referencia a las naciones de Europa occidental, que caracteriza al siglo XIX latinoamericano". El autor propone una cronología de los cambios en tres períodos.

De 1845 a 1867, año en que se desploma el Estado central colombiano, si es que alguna vez existió, "la referencia sirve más a alimentar los discursos, los debates y las discordias internas que a construir el Estado". La Europa imaginada sirve de pretexto en los conflictos de las facciones políticas que, poco a poco, se consolidan en partidos.

Hasta 1880, los liberales tratan de dar una administración viable al Estado, y para hacerlo, se inspiran en el estudio de la organización administrativa de los países europeos y en sus leyes nacionales, tratan de fundar una red de colegios calcada del modelo alemán, intentan provocar una inmigración europea. Por falta de consenso sobre el tema de la educación pública, estas reformas desembocan en una sangrienta guerra civil. Sin preparación política, el trasplante del modelo europeo termina en un desastre.

Finalmente, el tercer período va de 1880 a 1900; es el de la Regeneración: la ambición de los conservadores, que para ese entonces toman el poder, se une a la de sus predecesores liberales: construir un Estado y estabilizar la identidad nacional alrededor de valores simples y movilizadores. Mediante un discurso político "autenticista", los 
conservadores le dan la espalda, en apariencia, a los valores europeos para cultivar una diferencia, que toman como la garantía de su identidad. Esta resolución remodela, más que anula, la referencia a Europa, porque lejos de apartarse del viejo continente, los conservadores buscan allí mucha de su inspiración, al mismo tiempo que no cesan de denunciar el carácter extranjero de la ideología de sus adversarios liberales, inadecuado a las realidades colombianas. Se valoriza a la Madre Patria española, modelo de catolicidad, y la estabilidad de las instituciones inglesas. Al mismo tiempo, el gobierno intenta importar algunas instituciones desarrolladas por la III República francesa, que tuvo el mérito de resolver los problemas de inestabilidad que se planteaban, casi en los mismos términos que en Colombia. Frédéric Martinez ha caracterizado este período como el del "orden importado". Congregaciones religiosas para educar al pueblo pero manteniéndolo sometido a Dios y a las autoridades civiles, policía, cárceles, ejército; todo es copiado de Francia para dar vida a una República de Notables. Una vez más, el intento es un fracaso, a pesar de algunos éxitos parciales.

\section{DE EUROPA A COLOMBIA Y VICEVERSA: LOS MEDIADORES CULTURALES}

La afinidad cultural entre Colombia y Europa en el siglo XIX sería letra muerta sin la existencia de mediadores culturales. Aquí también el autor invierte el punto de vista habitual. El viajero por excelencia es el occidental que recorre comarcas lejanas; le siguen sabrosos relatos de viaje en los que la diferencia toma el sabor del exotismo. Retomando la astucia de Montesquieu en Cartas Persas, el autor analiza al viajero "exótico" que recorre el viejo mundo. El estudio prosopográfico de 580 colombianos habiendo viajado a Europa principalmente entre 1860 y 1880 permite restituir los pasos concretos de la difusión cultural de América hacia Europa pero por supuesto y sobretodo, de Europa hacia América. Vivaz y detalladamente el autor indica las motivaciones, a menudo literarias, de estos viajes iniciáticos, trae a la memoria los tipos de vida, comenta lo que éstos permiten: los colombianos formados en las universidades alemanas y francesas, al retornar al país desarrollan el comercio, la industria y la medicina, traen nuevas ideas de reformas políticas, administrativas o fiscales. Este microcosmos restringido, pero activo, ha desempeñado un rol seminal en Colombia a lo largo del siglo XIX.

Los viajeros colombianos fueron a buscar a Europa una superioridad y un origen. Ahora bien, es verdad que muchos se decepcionan por la mediocridad de los medios políticos o artísticos que habían adulado de lejos, o por la suciedad y la pobreza de las ciudades europeas con las cuales habían soñado tanto. Otros se deslumbran con lo que ven. Pero sea cual fuere su reacción, la experiencia del viaje suscita, al regreso, una reflexión sobre la "colombianidad". Los decepcionados buscan afirmar su diferencia con una Europa indigna de su prestigio; los entusiastas, menos numerosos, tratan de trasplantar las novedades admiradas sin tocar empero la identidad profunda y contradictoria — católica, republicana, rural— de su país. De hecho, el encuentro entre burguesías europeas y colombiana es con frecuencia objeto de amargura. Los patricios americanos son muy frecuentemente considerados como curiosos salvajes por la alta sociedad; en reacción brota en ellos el sentimiento de una separación entre las dos 
civilizaciones. Este desencanto americano frente a la ignorancia europea de América Latina da pie a una profunda reflexión sobre las particularidades nacionales. Anima la búsqueda de una vía propia hacia la modernidad. En esta parte de su estudio, Frédéric Martinez articula la historia social con la historia política y cultural. Escapando así del defecto común de los estudios de historia de las ideas que descuidan las modalidades concretas de los mecanismos de difusión intelectual.

\section{UN OCCIDENTE AMPLIADO}

La ambición del libro no se detiene en estas necesarias precisiones. Los factores coyunturales no pueden explicar por sí solos la centralidad de la referencia a Europa en los debates colombianos de la segunda mitad del siglo. El rechazo del modelo difusionista obliga a reconsiderar sin anacronismo las relaciones particulares que unen a Europa con Hispanoamérica. Los movimientos descolonizadores de los años 1950 y 1960 efectivamente concentraron la atención historiográfica sobre los fenómenos de resistencia o de dominación culturales y políticos. Desgraciadamente muchos de estos útiles estudios se dedicaban más a construir que a explicar sus objetos. El deseo de exaltar la visión de los vencidos dio a luz utopías identitarias. En efecto estas concepciones estáticas ponían frente a frente dos identidades puras - la del pueblo dominado contra la del pueblo dominante-, enfrentadas a muerte en el marco de una progresiva intervención occidental sobre el mundo. Desde hace veinte años se ha puesto el acento sobre los fenómenos de hibridación y de mestizaje biológico, político y cultural entre conjuntos humanos cuyas identidades son vistas como procesos o dinámicas más que como objetos estáticos. Los fenómenos de contra-aculturación y de intercambio "de abajo hacia arriba" cobrán interés (1). Los recientes genocidios ocurridos en Europa y África han hecho reflexionar a los investigadores sobre lo inconveniente de considerar como un absoluto la identidad de una comunidad étnica o nacional. La exaltación de la pureza cultural daba demasiados argumentos a líderes étnicos (2), pacíficos o guerreros. La globalización refuerza este proceso revisionista.

Dentro de esta perspectiva, lejos de oponer resistencia a una cultura hegemónica de origen europeo, las élites colombianas se creen herederas de la tradición del viejo continente - hasta por lo menos 1860- La Independencia no es vivida como una ruptura con occidente. Al contrario, al emanciparse de España, Colombia se colocó entre los primeros países donde se afirmaron el liberalismo político, la modernidad de los derechos humanos y el régimen representativo. Sobre este punto, no existen complejos en relación a la vieja Europa monárquica. Retomando la imagen de Bernard de Clairvaux, aunque Colombia es todavía un enano en la escala de las naciones, por lo menos es un enano encaramado sobre los hombros del gigante republicano, lo que le permite abarcar un horizonte político más amplio que aquel de las monarquías europeas, y de estar en la vanguardia del progreso. Este orgullo republicano se afirma sobre todo entre 1854 y 1867.

(1) Los estudios de Serge Gruzinski (por ejemplo, 1999) son característicos de esta nueva manera de abordar los intercambios culturales.

(2) Ver la reciente tesis de doctorado de Elisabeth Cunin sobre este tema (2000). 
Por este motivo América Latina republicana no se vio a sí misma como una periferia servil de Europa sino como un miembro más de una civilización común. La pertenencia asumida al mundo occidental permite la rápida circulación de las ideas políticas y de las novedades artísticas, culturales y técnicas, porque estos intercambios simbólicos se hacen en un mismo plano de civilización. Es verdad que las poblaciones rurales escapan frecuentemente de esta cultura canónica, urbana y elitista. Pero gracias a la escuela y a la acción civilizadora del Estado, los patricios de las capitales no pierden la esperanza de integrar a la nación a estas masas "amorfas". El estudio de Frédéric Martinez repudia el europeocentrismo ingenuo de las historiografías tanto del viejo continente como de América, mostrando que los intercambios entre ambos continentes se deben a la profundidad y a la intensidad de esta pertenencia a un mismo plano de civilización que juntos van construyendo. Por esta razón el nacionalismo colombiano es cosmopolita, como todos los nacionalismos y todas las identidades tanto en su origen como en su evolución. En este sentido, el magnífico trabajo de Frédéric Martinez contribuye a una profunda renovación de la reflexión sobre los intercambios culturales.

\section{THIBAUD}

\section{Referencias citadas}

CUNIN, E., 2000 - Le métissage dans la ville. Apparences raciales, ancrage territorial et construction de catégories à Cartagena (Colombie), Université de Toulouse.

GRUZINSKI, S., 1999 - La pensée métisse; Paris: Fayard. 